\title{
Cardiac disease in Down Syndrome: literature review and international expert consensus in collaboration with Down Syndrome International (DSi)
}

Andrew Constantine ${ }^{1,2}$, Robin Condliffe ${ }^{3}$, Paul Clift ${ }^{4}$, Robert Tulloh $^{5}$, Katrijn Jansen ${ }^{6}$, Konstantinos Dimopoulos ${ }^{1,2^{*}}$ and on behalf of the CHAMPION Steering Committee

\begin{abstract}
Background: Congenital heart disease is common in patients with Down syndrome, yet clinical recommendations relating to its diagnosis and management in this patient group are lacking.

Main body: We discuss the ongoing collaboration between an international panel of cardiovascular experts and expert stakeholders from Down Syndrome International, an international disabled people's organisation with membership of organisations and individuals from 136 countries worldwide. The aim of this collaboration is to describe best clinical practice, focusing on 10 key areas relating to Down syndrome and cardiac disease, from prenatal diagnosis to the care of patients in areas of differing resource availability.
\end{abstract}

Conclusions: The planned expert consensus statement on cardiac disease in people with Down syndrome aims to foster communication between experts, direct future research and inform future practice guidelines for the diagnosis and management of cardiovascular disease in people with Down syndrome.

Keywords: Down syndrome, Trisomy 21, Congenital heart disease, Epidemiology, Prenatal diagnosis, Cardiac surgery, Long-term outcomes, Healthcare resources

\section{Introduction}

Cardiovascular disease is one of the most common health problems in people with Down syndrome. Congenital heart disease (CHD) of various types complicates up to $50 \%$, and there is a predisposition to the development of pulmonary hypertension and other acquired cardiovascular conditions as a result of related comorbidities such as obesity and sleep apnoea.[1, 2] Even though the impact of cardiovascular conditions on the

\footnotetext{
* Correspondence: k.dimopoulos02@gmail.com

'Adult Congenital Heart Centre and National Centre for Pulmonary Hypertension, Royal Brompton Hospital, Royal Brompton and Harefield NHS Foundation Trust, SW3 6NP London, UK

${ }^{2}$ National Heart and Lung Institute, Imperial College London, London, UK Full list of author information is available at the end of the article
}

long-term outcome of people with Down syndrome is well-described,[3, 4] current Down syndrome-specific recommendations focus mainly on non-cardiovascular health. When cardiac disease is considered in clinical guidelines, the focus is on acquired cardiovascular conditions, e.g. lipid management, coronary artery and cerebrovascular disease, rather than on CHD. $[5,6]$ Furthermore, guidance for specialists who provide CHDspecific care to people with Down syndrome is lacking. Over recent decades, for better or worse, CHD management in people with Down syndrome has differed significantly to that of the general population, and between different countries and healthcare systems, and is a topic often neglected by the wider medical community. The 
goal of the proposed project is to develop an evidencebased expert consensus document for the diagnosis and management of CHD for children and adults with Down syndrome, which in the future may lead to the development of detailed practice guidelines in this area.

\section{Main body}

Advocacy for people with Down syndrome around the world is the focus of the work of Down Syndrome International (DSi), which includes the training and education of healthcare providers and of the Down syndrome community. DSi is an international disabled people's organisation with a membership of organisations and individuals from 136 countries worldwide, committed to improving the quality of life for people with Down syndrome.[7] Cardiovascular experts from around the world have joined forces with DSi to develop a state-of-the-art review and expert consensus statement on cardiac disease in people with Down syndrome. Ten key areas relating to the care of patients with Down syndrome and cardiac disease have been developed using feedback from key stakeholders from the DSi global network and the working group of experts, which will form the basis of the statement:

1 Incidence, present and future, and types of $\mathrm{CHD}$ in Down syndrome;

2 Best practice for prenatal and neonatal diagnosis, and specific management needs arising during this period;

3 Optimal timing of repair of CHD in Down syndrome and the risk of developing pulmonary hypertension;

4 Perioperative risks, complications and optimal care;

5 Long-term complications and outcome of CHD in Down syndrome;

6 Optimal follow-up and long-term care for patients with CHD and/or pulmonary hypertension and Down syndrome;

7 Acquired cardiac and non-cardiac comorbid considerations to aid heart disease-related decisionmaking;

8 The influence of learning disabilities on the practical management of patients with Down syndrome and $\mathrm{CHD}$;

9 The optimal approach to diagnose and manage patients with Down syndrome in areas of different resource availability, including healthcare resources;

10 Future research needs and challenges in Down syndrome research.

Expert consensus statements for each topic will be formed from a formal review and synthesis of the literature. The statements will address current best practice in diagnosis, repair and issues arising during lifelong follow-up, including promoting exercise to maintain cardiovascular health. Supporting text will review available evidence and differences that exist in the provision of care across borders and in different healthcare settings. The project will inform consultations and guide diagnosis, treatment and the long-term follow-up of people with Down syndrome affected by congenital heart and other cardiovascular diseases.

\section{Conclusions}

Through this work, we also aim to improve communication between experts across borders, stimulate discussion and the creation of training resources, direct future research and, ultimately, allow the development of international practice guidelines for the diagnosis and management of cardiovascular disease in people with Down syndrome.

\section{Abbreviations}

CHD: Congenital heart disease; DSi: Down Syndrome international

\section{Acknowledgements}

We are grateful to Down Syndrome International (DSi), and in particular to Andrew Boys (Executive Director, DSi) and Helen Powell (Programme Manager, DSi), for their collaboration in this project. We are also grateful to the continued efforts of the international expert working group: Ryo Inuzuka, MD, University of Tokyo Hospital, Japan; Gruschen Veldtman, MBChB, FRCP (UK), King Faisal Hospital, Saudi Arabia; Clifford Cua, MD, Nationwide

Children's Hospital, OH, USA; Edgar Tay, MBBS, MRCP (UK), MMed (Int Med), FAMS, FACC, FESC, National University Heart Centre, Singapore; Alexander Opotowsky, MD, MMSc, The Heart Institute, Cincinnati Children's Hospital, University of Cincinnati College of Medicine, OH, USA; Rafael AlonsoGonzalez, MD, Toronto General Hospital, Canada; George Giannakoulas, MD, PhD, AHEPA University Hospital, Thessaloniki, Greece; Rachel Cordina, MD,

Royal Prince Alfred Hospital, Sydney, Australia; Judith Namuyonga, MBBS, Uganda Heart Institute, Uganda; George Capone, MD, Down Syndrome Clinic and Research Center, Kennedy Krieger Institute, MD, USA; Charmaine Scott, OD, Bsc, MBBS, DCH, DM (Paeds), University Hospital of the West Indies, Jamaica; Francisco Alfaro, MD, Venocentro, El Salvador; Brian Chicoine, MD, Advocate Medical Group Adult Down Syndrome Center, IL, USA; Hong Gu, MD, PhD, Beijing Anzhen Hospital, Capital Medical University, Beijing, China; Alysa Limsuwan, MD, Mahidol University, Bangkok, Thailand; Werner Budts, $\mathrm{MD}$, PhD, KU Leuven, Belgium; Gerry Coghlan, MB, BCH, BAO, MD, MRCPI, FRCP (LON), Royal Free Hospital, London, UK;Craig Broberg, MD, OHSU Knight Cardiovascular Institute, Portland, Oregon, USA;and Tosin Majekodunmi, BSC (Hons), PhD, MBBS, MRCP (London), Euracare Multi-specialist Hospital, Nigeria.

\section{Authors' contributions}

A.C. drafted the initial manuscript, which was contributed to and revised by P.C., R.T., R.C., K.J., K.D.. All authors approved the final version of the manuscript prior to submission.

\section{Funding}

No funding was received for this manuscript.

Availability of data and materials

Not applicable.

Ethics approval and consent to participate

Not applicable (this manuscript does not report on or involve the use of any animal or human data or tissue). 


\section{Consent for publication}

Patient consent not applicable. All authors have given reviewed the final manuscript and have given their consent for publication.

\section{Competing interests}

Dr Constantine reports grants from Janssen Pharmaceuticals, outside the submitted work; Professor Tulloh reports personal fees and non-financial support from Janssen Pharmaceuticals, personal fees from Pfizer, personal fees from Abbott International, personal fees from GlaxoSmithKline, personal fees from Bayer, outside the submitted work; Dr Condliffe reports personal fees and non-financial support from Janssen Pharmaceuticals, personal fees from Bayer, personal fees from GlaxoSmithKline, outside the submitted work; Dr Clift reports grants, personal fees and non-financial support from Janssen Pharmaceuticals, personal fees from Bayer, outside the submitted work; Dr Jansen reports that she has no competing interest to declare; Professor Dimopoulos reports personal fees from Pfizer, grants, personal fees and nonfinancial support from Janssen Pharmaceuticals, outside the submitted work.

\section{Author details}

'Adult Congenital Heart Centre and National Centre for Pulmonary Hypertension, Royal Brompton Hospital, Royal Brompton and Harefield NHS Foundation Trust, SW3 6NP London, UK. ${ }^{2}$ National Heart and Lung Institute, Imperial College London, London, UK. ${ }^{3}$ Pulmonary Vascular Disease Unit, Royal Hallamshire Hospital, Sheffield, UK. ${ }^{4}$ Department of Cardiology, Queen Elizabeth Hospital Birmingham, Birmingham, UK. ${ }^{5}$ Bristol Heart Institute, University Hospitals Bristol and Weston NHS Foundation Trust, Bristol, UK. ${ }^{6}$ Adult Congenital and Paediatric Heart Unit, Freeman Hospital Newcastle Upon Tyne Hospitals NHS Foundation Trust, Newcastle Upon Tyne, UK.

Received: 26 October 2020 Accepted: 27 December 2020

Published online: 08 January 2021

\section{References}

1. Weijerman ME, van Furth $A M$, van der Mooren MD, van Weissenbruch MM, Rammeloo L, Broers CJM, Gemke RJBJ. Prevalence of congenital heart defects and persistent pulmonary hypertension of the neonate with Down syndrome. Eur J Pediatr. 2010;169:1195-9.

2. Marder L, Tulloh R, Pascall E. Cardiac problems in Down syndrome. Paediatrics Child Health. 2015;25:23-9.

3. Englund A, Jonsson B, Zander CS, Gustafsson J, Annerén G. Changes in mortality and causes of death in the Swedish Down syndrome population. Am J Med Genet A. 2013;161A:642-9.

4. Versacci P, Di Carlo D, Digilio MC, Marino B. Cardiovascular disease in Down syndrome. Curr Opin Pediatr. 2018;30:616-22.

5. Tsou AY, Bulova P, Capone G, et al. Medical Care of Adults With Down Syndrome: A Clinical Guideline. JAMA. 2020;324:1543-56.

6. Bull MJ, the Committee on Genetics. Health Supervision for Children With Down Syndrome. Pediatrics. 2011;128:393-406.

7. Health. In: Down Syndrome International. https://www.ds-int.org/health. Accessed 28 Sep 2020

\section{Publisher's Note}

Springer Nature remains neutral with regard to jurisdictional claims in published maps and institutional affiliations. 